\title{
Protective effect of fluvastatin on influenza virus infection
}

\author{
JING PENG $^{1,2}$, DINGMEI ZHANG ${ }^{1}$, YU MA $^{1}$, GUOLING WANG $^{3}$, ZHONGMIN GUO $^{4}$ and JIAHAI LU ${ }^{1}$ \\ ${ }^{1}$ School of Public Health, State Ministry of Education, Key Laboratory of Tropical Diseases Control Research, \\ Sun Yat-sen University, Guangzhou, Guangdong 510080; ${ }^{2}$ Baoan Center for Disease Control and Prevention, Shenzhen, \\ Guangdong 518101; ${ }^{3}$ Haizhu Center for Disease Control and Prevention, Guangzhou, Guangdong 510288; \\ ${ }^{4}$ Experimental Animal Center, Sun Yat-sen University, Guangzhou, Guangdong 510080, PR China
}

Received July 12, 2013; Accepted February 27, 2014

DOI: $10.3892 / \mathrm{mmr} .2014 .2076$

\begin{abstract}
Statins are 3-hydroxy-3-methylglutaryl coenzyme A reductase inhibitors and have pleiotropic effects. It has been suggested that statins may be a potential treatment during the next influenza pandemic. In a previous study we found that a statin/caffeine combination protects BALB/c mice against Influenza A, subtypes haemagglutinin type 5 and neuraminidase type 1 (H5N1), H3N2 and H1N1 infection. The effect of statins alone on influenza virus infection, however, is not known. In this study, it was investigated whether fluvastatin is capable of inhibiting influenza A virus replication in vitro. The results demonstrated that the synthesis of viral RNA and protein was affected by fluvastatin treatment. Virus production was markedly reduced when fluvastatin was administered simultaneously with the virus; however, a greater inhibition was observed when fluvastatin was added following viral adsorption. The selectivity index [SI; $50 \%$ cytotoxic concentration $\left(\mathrm{CC}_{50}\right) / 50 \%$ inhibition concentration $\left.\left(\mathrm{IC}_{50}\right)\right]$, however, was only 21. It was further demonstrated that fluvastatin protects host cells against influenza-induced inflammation by reducing the production of tumour necrosis factor- $\alpha$, interleukin 8 and interferon $\gamma$. In conclusion, the results demonstrated that fluvastatin exerted a minor inhibitory effect on influenza virus infection, which involved anti-inflammatory activities.
\end{abstract}

\section{Introduction}

In July 2009, the World Health Organization (WHO) declared a pandemic due to a novel influenza virus, haemagglutinin type 1 and neuraminidase type 1 (H1N1) (1), which raised serious public concern (2). At present, vaccines and anti-influenza drugs are used for the treatment and prevention of influenza $(3,4)$.

Correspondence to: Professor Jiahai Lu or Dr Dingmei Zhang, School of Public Health, State Ministry of Education, Key Laboratory of Tropical Diseases Control Research, Sun Yat-sen University, 74 Zhongshan 2 Road, Guangzhou, Guangdong 510080, P.R. China

E-mail: lujiahai@mail.sysu.edu.cn

E-mail: zhdinggm@mail.sysu.edu.cn

Key words: fluvastatin, influenza virus, virus infection
However, the number of vaccines currently available is insufficient. Failure to anticipate the circulating strains also reduces the efficacy of the vaccines $(5,6)$. Two classes of approved antiviral drugs are available at present, neuraminidase inhibitors and M2 channel inhibitors (7). However, the use of these drugs is limited due to the emergence of drug-resistant viruses $(8,9)$; therefore, the development of novel, effective antiviral drugs is critical in order to control and treat influenza infections.

Statins are 3-hydroxy-3-methylglutaryl coenzyme A (HMG-CoA) reductase inhibitors, and are widely used in lipid-lowering therapy. Studies have shown that statins have pleiotropic effects (10-12), including anti-inflammatory and immunomodulatory effects, which may provide a potential therapeutic treatment against influenza (13). Influenza infection is characterized by increased plasma concentrations of proinflammatory cytokines, known as a 'cytokine storm' (14). Anti-inflammatory and immunomodulatory agents are potential antiviral drugs. Statins have been shown to exert antimicrobial effects against certain organisms, and they have also been reported to be active against a broad spectrum of viruses $(15,16)$. In addition, observational studies have suggested that statins may reduce mortality in patients with influenza $(17,18)$. We previously reported that a statin/caffeine combination protects BALB/c mice against H5N1, H3N2 and H1N1 infection. The effect of statin alone on influenza virus infection; however, is not known. Fluvastatin is a member of the statin family. In this study, the inhibition effect of fluvastatin on influenza A virus infection was investigated, as well as the mechanism of action in cultured cells.

\section{Materials and methods}

Cells, virus strains and reagents. Madin-Darby canine kidney (MDCK) cells and a human epithelial lung cell line (A549) obtained from the Experimental Animal Center of Sun Yat-sen University (Guangzhou, China) were grown in minimum essential medium (MEM; Invitrogen Life Technologies, Carlsbad, CA, USA) and Dulbecco's Modified Eagle medium/Nutrient Mixture F12 (DMEM/F12; Hyclone, Thermo Fisher Scientific, Waltham, MA, USA), respectively, with $10 \%$ heat-inactivated fetal bovine serum (FBS), penicillin (100 U/ml), and streptomycin $(100 \mu \mathrm{g} / \mathrm{ml})$. Pandemic 2009 strain A/Guangdong/03/2009 (H1N1) was provided by Guangzhou Center for Disease Control and Prevention (Guangzhou, China) 
and was propagated in MDCK cells. The fluvastatin and Oseltamivir was supplied by LGC (Teddington, UK). All virus work was performed under BL2+ safety conditions.

Viral titer assay. Monolayer MDCK cells $\left(6 \times 10^{5}\right.$ cells/well) in six-well plates were infected with a serially diluted virus. Following adsorption for $2 \mathrm{~h}$ at $37^{\circ} \mathrm{C}$, cells were washed twice and supplemented with MEM containing $0.9 \%$ agarose (Oxoid Ltd., Basingstoke, UK), 0.4\% bovine serum albumin (Gibco ${ }^{\circledR}$-BRL, Carlsbad, CA, USA) and $4 \mu \mathrm{g} / \mathrm{ml}$ trypsin (Gibco ${ }^{\circledR}-\mathrm{BRL}$ ). Plaques were visualized 2-3 days later, then fixed with $10 \%$ formaldehyde and stained with $1 \%$ crystal violet.

Cytotoxicity test and $\mathrm{IC}_{50}$ determination. MDCK or A549 cells were seeded onto 96 -well plates $\left(5 \times 10^{5}\right.$ cells/well $)$ and incubated for $24 \mathrm{~h}$. Following treatment with MEM containing two-fold serially diluted fluvastatin for $48 \mathrm{~h}$, the medium was removed and $50 \mu \mathrm{l}$ MTT (Sigma, St. Louis, MO, USA) was added into each well and incubated for $3 \mathrm{~h}$ at $37^{\circ} \mathrm{C}, 5 \% \mathrm{CO}_{2}$. Dimethyl sulphoxide (DMSO; $150 \mu \mathrm{l} /$ well; Sigma) was then added, and the absorbance of the cells was determined at $490 \mathrm{~nm}$. The $50 \%$ cytotoxic concentration $\left(\mathrm{CC}_{50}\right)$ was calculated. Anti-influenza virus activity of fluvastatin was analysed and the $50 \%$ inhibition concentration $\left(\mathrm{IC}_{50}\right)$ was determined. MDCK cells were infected with H1N1 and a multiplicity of infection (MOI) of 0.1 for $1 \mathrm{~h}$. Maintenance medium containing serial two-fold dilutions of fluvastatin $(0-20 \mu \mathrm{g} / \mathrm{ml})$ was added and the cells were then incubated for $48 \mathrm{~h}$ at $37^{\circ} \mathrm{C}, 5 \% \mathrm{CO}_{2}$. The MTT assay was performed as described above. Oseltamivir (0-4 $\mu \mathrm{g} / \mathrm{ml}$; ) was used as the positive control.

Quantitative polymerase chain reaction ( $q P C R)$. MDCK cells were infected with H1N1 (MOI of 0.1), and were treated with or without fluvastatin $(0-20 \mu \mathrm{g} / \mathrm{ml})$. Total RNA was extracted 12 and $24 \mathrm{~h}$ following infection using the QIAamp ${ }^{\circledR}$ MinElute Virus Spin kit (Qiagen, Venlo, The Netherlands). The primer sequences used for the qPCR of viral RNA were as follows: Forward, 5'-GAGGATGGTGCTTTCTGCTTTT-3' and reverse, 5'-AGTTCTCTCATCCACTTTCCGTCT-3'. $\beta$-actin was used as an internal control of cellular RNA, and the primer sequences used were as follows: Forward, 5'-CGTGCGTGACATCAAGGAAGAAG-3' and reverse, 5'-GGAACCGCTCGTTGCCAATG-3'.

Total RNA was reverse transcribed into cDNA using PrimeScript ${ }^{\circledR}$ RT Master Mix (Perfect Real Time) (Takara Bio Inc., Shiga, Japan). qPCR was conducted using $2 \mu \mathrm{l}$ cDNA and SYBR $^{\circledR}$ Premix Ex Taq II (Takara Bio Inc.). Cycling conditions for qPCR were as follows: $95^{\circ} \mathrm{C}$ for $30 \mathrm{sec}$, followed by 40 cycles of $95^{\circ} \mathrm{C}$ for $5 \mathrm{sec}$ and $60^{\circ} \mathrm{C}$ for $34 \mathrm{sec}$. $\beta$-actin mRNA was used as a loading control. qPCR was conducted using the ABI Prism ${ }^{\circledR} 7500$ sequence detection system (Applied Biosystems, Foster City, CA, USA). Data are expressed as the relative differences between control and treated cells following normalization to $\beta$-actin expression.

Immunofluorescence assay. MDCK cells were plated on glass coverslips and were exposed to the H1N1 virus at an MOI of 0.1 for $1 \mathrm{~h}$, then maintenance medium in the presence or absence of $20 \mu \mathrm{g} / \mathrm{ml}$ fluvastatin were added. Twelve hours following infection, the cells were fixed with $4 \%$ paraformaldehyde for $10 \mathrm{~min}$ and permeabilised with 1\% Triton X-100 (Sigma-Aldrich, St. Louis, MO, USA) in phosphate-buffered saline (PBS) for $10 \mathrm{~min}$. Cells were then incubated with rat anti-nucleoprotein (anti-NP) monoclonal antibodies (Santa Cruz Biotechnology, Inc., Santa Cruz, CA, USA) at $37^{\circ} \mathrm{C}$ for $1 \mathrm{~h}$, then washed with $0.5 \%$ NP-40 in PBS and incubated with fluorescein isothiocyanate-conjugated goat anti-rabbit monoclonal antibody (Santa Cruz Biotechnology, Inc.) for $1 \mathrm{~h}$. Subsequently, cells were stained with 4',6'-diamidino-2-phenylindole dihydrochloride (Roche, Mannheim, Germany). The cells were mounted and observed using a fluorescence microscope (DMI3000B; Leica Microsystems, Wetzlar, Germany).

Time-of-addition assay. MDCK cells $\left(5 \times 10^{5}\right.$ cells/well) were seeded in six-well plates and incubated for $24 \mathrm{~h}$, and the virus (MOI of 1) was added to cells for $1 \mathrm{~h}$ at $37^{\circ} \mathrm{C}$. Fluvastatin was added from -9 to $-1 \mathrm{~h}$ (prior to adsorption), -1 to $0 \mathrm{~h}$ (during adsorption) and 0 to $8 \mathrm{~h}$ (post-adsorption). Following administration of fluvastatin, the cells were washed with PBS and incubated with fresh medium until $8 \mathrm{~h}$ post-infection. The supernatant was collected and frozen at $-80^{\circ} \mathrm{C}$ prior to determination of the viral yield using the plaque assay.

Analysis of cytokine production. A549 cells in a six-well plate were infected with H1N1 with an MOI of 1 for $1 \mathrm{~h}$, then maintenance medium in the presence or absence of $20 \mu \mathrm{g} / \mathrm{ml}$ fluvastatin was added. Culture supernatants were collected and the concentration of cytokines was analysed 24, 36 and $48 \mathrm{~h}$ following infection. Cytokine assays were performed using Quantibody Human Inflammation Array (product number, QAH-INF-1; RayBiotech Inc., Norcross, GA, USA).

Neuraminidase inhibition assay. Equal volumes of virus and fluvastatin that were two-fold serially diluted with PBS were mixed and incubated for $30 \mathrm{~min}$ at room temperature, and the reaction was initiated by addition of 2'-(4-methylumbelliferyl)- $\alpha-\mathrm{D}-\mathrm{N}$-acetylneuraminic acid (Sigma). A total of $500 \mathrm{mM}$ carbonate buffer ( $\mathrm{pH}$ 10.7) was added to terminate the reaction. The fluorescence was measured by a Promega GloMax 96 Microplate Luminescence detector (Promega Corporation, Madison, WI, USA) at $365 \mathrm{~nm}$ (excitation) and $450 \mathrm{~nm}$ (emission).

Statistical analysis. A one-way analysis of variance followed by Bonferroni's method was used to compare the differences between the groups. $\mathrm{P}<0.05$ was considered to indicate a statistically significant difference. The $\mathrm{IC}_{50}$ and $\mathrm{CC}_{50}$ values were calculated using GraphPad Prism 5 (GraphPad Software, Inc., La Jolla, CA, USA).

\section{Results}

Cytotoxicity of fluvastatin and $I C_{50}$ determination. MDCK cells were incubated in the presence of two-fold fluvastatin serial dilutions for $48 \mathrm{~h}$. The viability of cells was then estimated using the MTT assay. As shown in Fig. 1A, the $\mathrm{CC}_{50}$ value was $90.3 \mu \mathrm{g} / \mathrm{ml}$. When MDCK cells were incubated with fluvastatin following virus adsorption, the cytopathic effect formation was decreased in MDCK cells that were infected with pandemic 2009 strain 
A

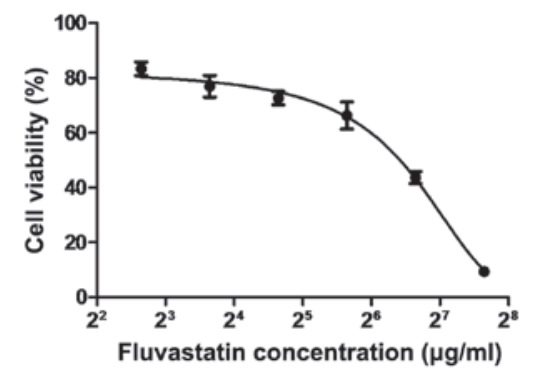

B

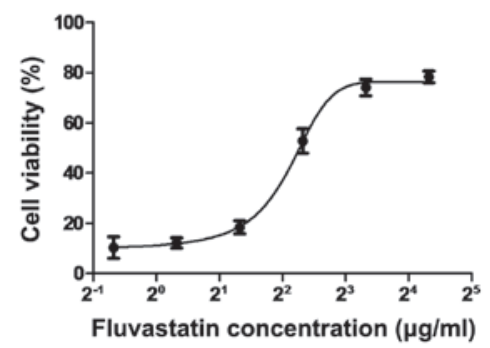

Figure 1. Cytotoxicity of fluvastatin and $\mathrm{IC}_{50}$ determination. (A) Cytotoxicity of fluvastatin to MDCK cells. MDCK cells were treated with serial concentrations $(\mu \mathrm{g} / \mathrm{ml})$ of fluvastatin for $48 \mathrm{~h}$. The cell viability was determined using the MTT assay and the absorbance was measured at $490 \mathrm{~nm}$. Data were determined in quadruplicate and presented as the mean \pm standard deviation. (B) Inhibition of influenza infection. MDCK cells were infected with haemagglutinin type 1 and neuraminidase type 1 (multiplicity of infection, 0.1 ) and then incubated with two-fold serial dilutions of fluvastatin for $48 \mathrm{~h}$. Inhibition of cell viability was determined using the MTT assay. Samples were tested in triplicate and results are shown as the mean \pm standard deviation. $\mathrm{IC}_{50}, 50 \%$ inhibition concentration; MDCK, Madin-Darby canine kidney.

A

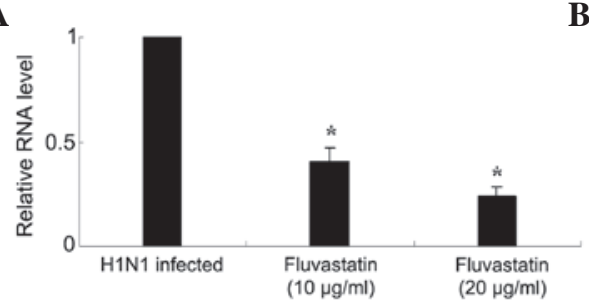

$12 \mathrm{~h}$

B

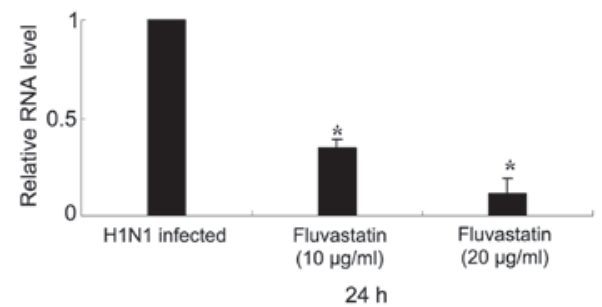

Figure 2. Effect of fluvastatin on influenza viral nucleoprotein RNA levels measured using qPCR. MDCK cells were infected with influenza virus (multiplicity of infection, 0.1). Virus was removed after $1 \mathrm{~h}$, and cells were treated with or without fluvastatin. The total RNA was extracted at 12 and $24 \mathrm{~h}$ following virus infection, respectively. The amount of RNA was analysed using qPCR and influenza viral RNA levels were normalized against $\beta$-actin. (A) $12 \mathrm{~h}$ post-infection; (B) 24 h post infection. " $\mathrm{P}<0.05$, compared with H1N1-infected cells control group. qPCR, quantitative polymerase chain reaction; MDCK cells, Madin-Darby canine kidney cells; H1N1, haemagglutinin Type 1 and neuraminidase Type 1.

A

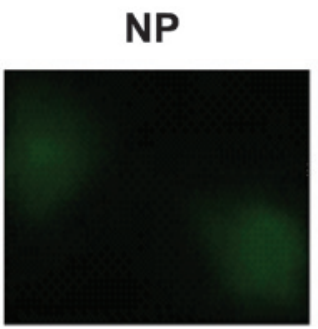

B

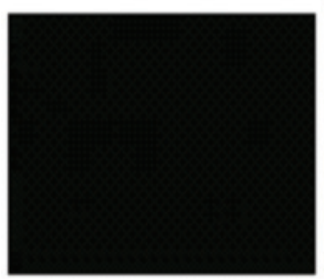

DAPI
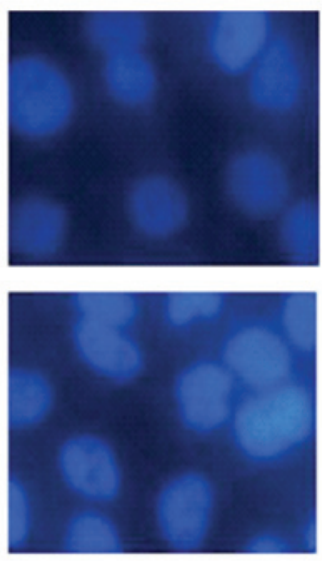

Merge
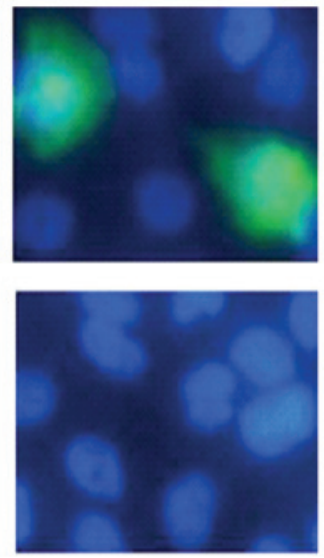

Figure 3. Inhibition of influenza viral nucleoprotein synthesis by fluvastatin. Influenza virus-infected MDCK cells on coverslips were incubated with or without fluvastatin following infection. The cells were fixed $12 \mathrm{~h}$ following infection and treated with a primary anti-NP antibody and fluorescein isothiocyanate-conjugated goat anti-rabbit secondary antibody. The production of viral protein was detected by immunofluorescence microscopy. (A) Cells were infected with influenza virus and harvested $12 \mathrm{~h}$ post-infection. (B) Virus-infected cells were harvested $12 \mathrm{~h}$ post-infection, and fluvastatin was added following virus adsorption. MDCK cells, Madin-Darby canine kidney cells; NP, nucleoprotein.

A/Guangdong/03/2009 (H1N1) at an MOI of 0.1 (data not shown). To investigate the effect of fluvastatin on influenza, MDCK cells were incubated with different concentrations of fluvastatin following virus adsorption, and the viability of the cells was determined. It was found that at the concentration range of $<20 \mu \mathrm{g} / \mathrm{ml}$, fluvastatin exerted an inhibitory effect on influenza virus infection, and the $\mathrm{IC}_{50}$ value of fluvastatin was $\sim 4.3 \mu \mathrm{g} / \mathrm{ml}$ (Fig. 1B). The $\mathrm{IC}_{50}$ value of the positive control (oseltamivir) was $0.8 \mu \mathrm{g} / \mathrm{ml}$. The selectivity index $\left(\mathrm{CC}_{50} / \mathrm{IC}_{50}\right)$ for fluvastatin was 21 .

The cytotoxicity of fluvastatin on A549 cells was also investigated. At a concentration of $300 \mu \mathrm{g} / \mathrm{ml}$, fluvastatin did 
A

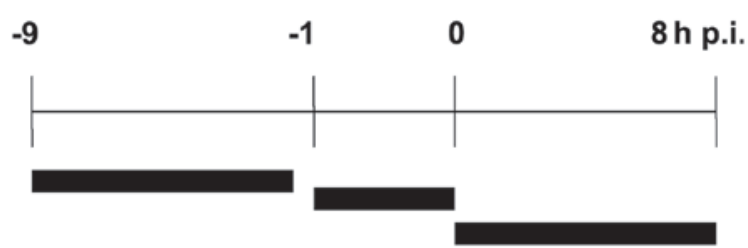

B

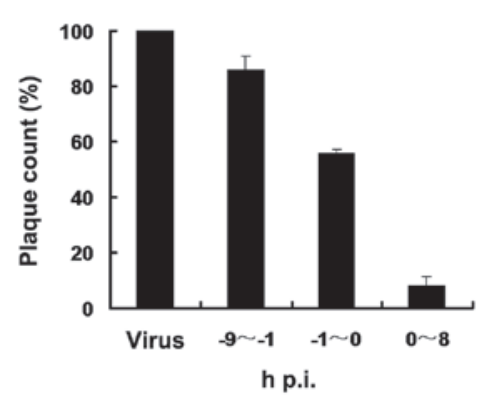

C

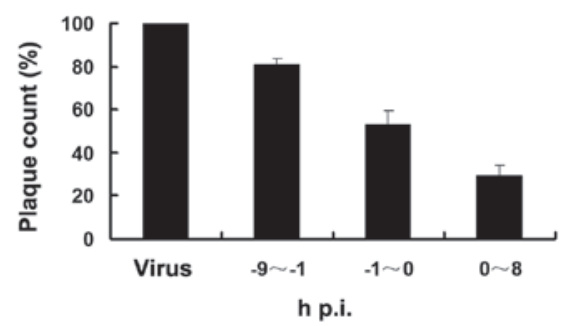

Figure 4. Time-of-addition assay. MDCK cells were inoculated with haemagglutinin type 1 and neuraminidase type 1 virus at a multiplicity of infection of 1 between -1 and $-0 \mathrm{~h}$. Viral yield was determined $8 \mathrm{~h}$ post-infection using the plaque assay. (A) Fluvastatin was added at indicated times. Following each incubation period, the medium containing fluvastatin was removed and the fresh medium was added. (B and $\mathrm{C}$ ) The percentage of the mean plaque formation relative to the control was calculated at fluvastatin concentrations of (B) $20 \mu \mathrm{g} / \mathrm{ml}$ and (C) $10 \mu \mathrm{g} / \mathrm{ml}$. Two independent experiments were performed. MDCK cells, Madin-Darby canine kidney cells; p.i., post-infection.

not exhibit any detrimental effects on cell viability (data not shown).

Fluvastatin inhibits viral RNA and protein synthesis. The inhibitory effect of fluvastatin on influenza virus replication was determined by qPCR. Fluvastatin $(<20 \mu \mathrm{g} / \mathrm{ml})$ significantly reduced intracellular RNA expression of influenza virus NP in H1N1-infected MDCK cells $12 \mathrm{~h}$ post-infection. Expression of $\mathrm{NP}$ was further reduced $24 \mathrm{~h}$ post-infection (Fig. 2).

The inhibition of fluvastatin on viral NP expression was further investigated using immunofluorescence microscopy. MDCK cells were exposed to H1N1 virus (MOI of 0.1) for $1 \mathrm{~h}$ and then incubated with fluvastatin $(20 \mu \mathrm{g} / \mathrm{ml})$. Cells were stained for NP $12 \mathrm{~h}$ post-infection. The results showed that NP expression was decreased in the presence of fluvastatin (Fig. 3).

Inhibitory effects of fluvastatin on different stages of viral replication. The time-of-addition assay was used to analyse the effect of fluvastatin on virus yield in MDCK cells when fluvastatin was administered at different times relative to virus infection. The anti-viral effect of fluvastatin was
A

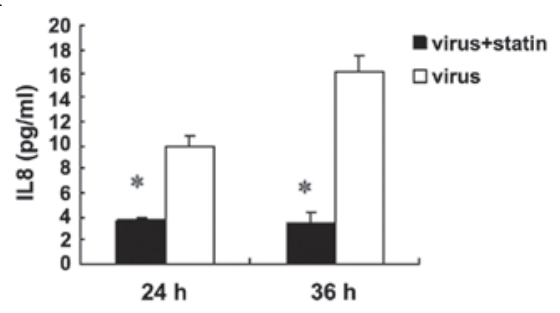

B

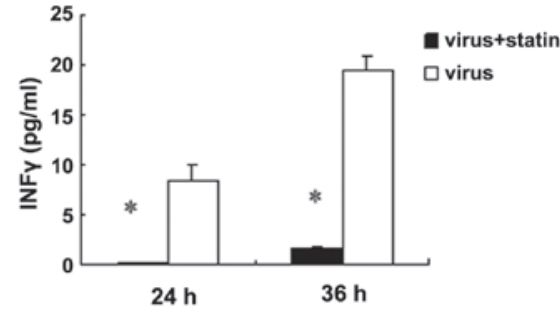

C

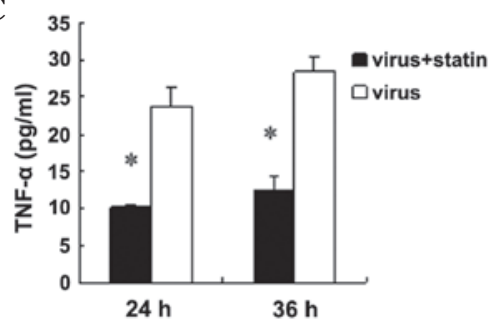

Figure 5. Effect of fluvastatin on H1N1-induced expression of cytokines in A549 cells. The release of cytokines was determined in the supernatant of H1N1-infected A549 cells in the presence of fluvastatin and non-treated virus control 24 or $36 \mathrm{~h}$ post-infection. Non-infected cells served as controls. ${ }^{*} \mathrm{P}<0.05$, compared with the non-treated virus control. H1N1, haemagglutinin type 1 and neuraminidase type 1 ; IL8, interleukin 8 ; IFN $\gamma$, interferon $\gamma$; TNF- $\alpha$, tumour necrosis factor- $\alpha$.

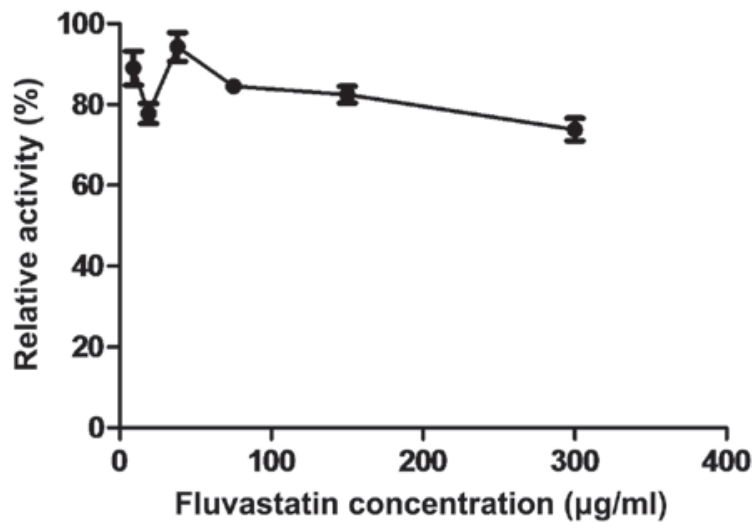

Figure 6. Effect of fluvastatin on the viral neuraminidase activity. Viruses were incubated with two-fold diluted fluvastatin for $30 \mathrm{~min}$ at room temperature. 2'-(4-methylumbelliferyl)- $\alpha$-D-N-acetylneuraminic acid was added to the mixture and the reaction was terminated with $500 \mathrm{mM}$ carbonate buffer ( $\mathrm{pH}$ 10.7). The neuraminidase activity was investigated using the fluorometric assay. Values are presented as the mean \pm standard deviation of three independent experiments.

determined following administration of fluvastin at three time-points, respectively (Fig. 4A). The viral plaque formation was observed and the plaques were counted by visual examination. 
When fluvastatin $(20 \mu \mathrm{g} / \mathrm{ml})$ was added prior to virus adsorption (Fig. 4B), a partial reduction in progeny virus production was detected compared with the untreated virus-infected cells. Fluvastatin exhibited an inhibitory effect when added during the adsorption period, and the addition of fluvastatin following viral adsorption caused a further decrease in progeny virus production. The inhibitory effects were also detected at the final concentration of $10 \mu \mathrm{g} / \mathrm{ml}$ fluvastatin (Fig. 4C).

Fluvastatin decreases the release of cytokines in H1N1-infected A549 cells. Influenza infection results in the increased production of cytokines; therefore, it was investigated whether this response was altered by fluvastatin treatment. The results showed that fluvastatin did not suppress cytokine expression in non-infected cells (data not shown). Baselines of cytokine were very low in non-infected cells. It was found that fluvastatin $(20 \mu \mathrm{g} / \mathrm{ml})$ reduced the release of tumour necrosis factor- $\alpha$ (TNF- $\alpha$ ), interleukin 8 (IL8) and interferon $\gamma$ (IFN $\gamma$ ) in the supernatants of H1N1-infected A549 cells 24 and $36 \mathrm{~h}$ post-infection (Fig. 5). By contrast, fluvastatin did not suppress secretion of seven other cytokines (data not shown). In addition, since the enhancement of the neuraminidase activity in host cells may reflect the virus infection, the inhibitory effect of fluvastatin on neuraminidase was evaluated in this study. However, no significant effect was observed (Fig. 6).

\section{Discussion}

At present, influenza treatment options are expensive and result in side effects; therefore, novel, effective and inexpensive treatments against influenza are required (19). Statins have been of recent interest due to their pleiotropic effects (20). An in vitro study reported that statins disrupt the replication of hepatitis $\mathrm{C}$ virus by inhibition of prenylation (21). In other studies, it was shown in vivo that statins exhibit direct anti-human immunodeficiency virus 1 (HIV-1) effects by targeting Rho $(22,23)$. In addition, another study demonstrated in vivo and in vitro that lovastatin may inhibit respiratory syncytial virus by reducing cell-to-cell fusion (16). Epidemiological evidence has also shown that statins improve poor clinical outcomes in observational studies of patients with sepsis, community-acquired pneumonia and influenza-related pneumonia (24-28). We previously found that a statin/caffeine combination protects $\mathrm{BALB} / \mathrm{c}$ mice against H5N1, H3N2 and H1N1 infection (29); however, it was not elucidated whether statins alone had an effect on viral infection. Therefore, in the current study, it was investigated whether statin is capable of inhibiting influenza virus replication.

The results of this study demonstrated that fluvastatin inhibited H1N1 influenza virus replication in H1N1-infected MDCK and A549 cells; however, the cytotoxicity of fluvastatin was higher in MDCK cells compared with that in A549 cells. This may be due to the different origins of the MDCK and A549 cells. Fluvastatin was shown to have an inhibitory effect post-infection, possibly by inhibiting the expression of cytokines. In particular, fluvastatin diminished the expression of TNF- $\alpha$, IL8 and IFN $\gamma$. Several anti-inflammatory and immunomodulatory drugs, including celecoxib and mesalazine, have previously been reported to influence influenza virus replication $(30,31)$. In this study it was shown that fluvastatin also inhibits viral RNA replication. However, the value of selectivity index was only 21 ; therefore, the inhibitory effect was limited.

Node et al (32) demonstrated that the administration of statins was associated with a reduction in the plasma concentrations of TNF- $\alpha$ and IL6 (32). Radigan et al (33) observed that rosuvastatin did not attenuate the severity of influenza A-induced lung injury in influenza A-infected $\mathrm{C} 57 \mathrm{Bl} / 6$ mice, which is inconsistent with our results. However, a longer duration of treatment may have had an effect (33). Belser et al (34) reported that simvastatin showed relatively little efficacy in treating the influenza virus infection in $\mathrm{BALB} / \mathrm{c}$ mice. Additionally, simvastatin treatment appeared to increase the time to death, but these findings were not statistically significant (34). Different virus types and statins were used in these studies, which may explain the conflicting results observed.

Cytokines, including TNF- $\alpha$ and IL6, have been implicated in weight loss during influenza infection (35). Further in vivo investigation is required to enhance the understanding of antiviral activity of fluvastatin. It is not yet known whether fluvastatin also attenuates the severity of influenza A infection by reducing the levels of these cytokines in vivo.

In conclusion, the results of the present study suggest that fluvastatin exerts a minor inhibitory effect on influenza virus infection in vitro. However, these results require further investigation in vivo.

\section{Acknowledgements}

The study was supported by the National Natural Science Foundation of China (nos. 81172735 and 81201283) and Guangdong Provincial Scientific and Technological Planning Project (no. 2010B031600076).

\section{References}

1. Kok J and Dwyer DE: How common was 2009 pandemic influenza A H1N1? Lancet Infect Dis 11: 423-424, 2011.

2. World Health Organization: Pandemic (H1N1) - update 112. http://wwwwhoint/csr/don/2010_08_06/en/indexhtml. Accessed November 10, 2011.

3. Memoli MJ, Morens DM and Taubenberger JK: Pandemic and seasonal influenza: therapeutic challenges. Drug Discov Today 13: 590-595, 2008.

4. Cox MM: Pandemic influenza: overview of vaccines and antiviral drugs. Yale J Biol Med 78: 321-328, 2005.

5. Podolec P and Kopeć G: Influenza vaccines for prevention of cardiovascular diseases. Kardiol Pol 65: 612-615, 2007 (In Polish)

6. Lambert LC and Fauci AS: Influenza vaccines for the future. N Engl J Med 363: 2036-2044, 2010.

7. Sugrue RJ, Tan BH, Yeo DS and Sutejo R: Antiviral drugs for the control of pandemic influenza virus. Ann Acad Med Singapore 37: 518-524, 2008.

8. Moss RB, Davey RT, Steigbigel RT and Fang F: Targeting pandemic influenza: a primer on influenza antivirals and drug resistance. J Antimicrob Chemother 65: 1086-1093, 2010.

9. Fedson DS: Confronting an influenza pandemic with inexpensive generic agents: can it be done? Lancet Infect Dis 8: 571-576, 2008 .

10. Tleyjeh IM, Kashour T, Hakim FA, et al: Statins for the prevention and treatment of infections: a systematic review and meta-analysis. Arch Intern Med 169: 1658-1667, 2009.

11. Zhou Q and Liao JK: Pleiotropic effects of statins: basic research and clinical perspectives. Circ J 74: 818-826, 2010. 
12. Corsini A, Ferri N and Cortellaro M: Are pleiotropic effects of statins real? Vasc Health Risk Manag 3: 611-613, 2007.

13. Terblanche M, Smith TS and Adhikari NK: Statins, bugs and prophylaxis: intriguing possibilities. Crit Care 10: 168, 2006.

14. Tisoncik JR, Korth MJ, Simmons CP, Farrar J, Martin TR and Katze MG: Into the eye of the cytokine storm. Microbiol Mol Biol Rev 76: 16-32, 2012.

15. Montoya CJ, Jaimes F, Higuita EA, et al: Antiretroviral effect of lovastatin on HIV-1-infected individuals without highly active antiretroviral therapy (The LIVE study): a phase-II randomized clinical trial. Trials 10: 41, 2009.

16. Gower TL and Graham BS: Antiviral activity of lovastatin against respiratory syncytial virus in vivo and in vitro. Antimicrob Agents Chemother 45: 1231-1237, 2001.

17. Frost FJ, Petersen H, Tollestrup K and Skipper B: Influenza and COPD mortality protection as pleiotropic, dose-dependent effects of statins. Chest 131: 1006-1012, 2007.

18. Kwong JC, Li P and Redelmeier DA: Influenza morbidity and mortality in elderly patients receiving statins: a cohort study. PLoS One 4: e8087, 2009.

19. Hayden F: Developing new antiviral agents for influenza treatment: what does the future hold? Clin Infect Dis 48 (Suppl 1) S3-S13, 2009.

20. Nair P and Roguin A: Statins and the acute coronary syndrome: 'the early bird catches the worm'. Int J Clin Pract 60: 716-727, 2006.

21. Ye J, Wang C, Sumpter R Jr, Brown MS, Goldstein JL and Gale M Jr: Disruption of hepatitis $C$ virus RNA replication through inhibition of host protein geranylgeranylation. Proc Nat Acad Sci USA 100: 15865-15870, 2003.

22. del Real G, Jiménez-Baranda S, Mira E, et al: Statins inhibit HIV-1 infection by down-regulating Rho activity. J Exp Med 200: 541-547, 2004.

23. Moncunill G, Negredo E, Bosch L, et al: Evaluation of the anti-HIV activity of statins. AIDS 19: 1697-1700, 2005.

24. Janssen NE, van Lelyveld SF, Hoepelman AI, Gras L, Groenwold RH and Oosterheert JJ: The effect of statin therapy on pneumonia in an HIV-infected population in the Netherlands. J Infect 67: 238-241, 2013.
25. Grau AC and George SM: Improved outcomes in community-acquired pneumonia with prior statin use. Am J Med 122: e15, author reply e17, 2009.

26. Chalmers JD, Singanayagam A, Murray MP and Hill AT: Prior statin use is associated with improved outcomes in community-acquired pneumonia. Am J Med 121: 1002-1007, 2008.

27. Guo YF and Hu DY: Statin use and reduced prevalence of sepsis. Zhonghua Nei Ke Za Zhi 46: 798-800, 2007 (In Chinese).

28. Almog Y, Shefer A, Novack V, et al: Prior statin therapy is associated with a decreased rate of severe sepsis. Circulation 110 880-885, 2004

29. Liu Z, Guo Z, Wang G, et al: Evaluation of the efficacy and safety of a statin/caffeine combination against H5N1, H3N2 and H1N1 virus infection in BALB/c mice. Eur J Pharm Sci 38: 215-223, 2009.

30. Jin $\mathrm{Y}$, Zhang G, Hu Y, et al: Inhibition of highly pathogenic avian $\mathrm{H} 5 \mathrm{~N} 1$ influenza virus propagation by RNA oligonucleotides targeting the PB2 gene in combination with celecoxib. J Gene Med 13: 243-249, 2011.

31. Hui DS, Lee N and Chan PK: Adjunctive therapies and immunomodulatory agents in the management of severe influenza. Antiviral Res 98: 410-416, 2013.

32. Node K, Fujita M, Kitakaze M, Hori M and Liao JK: Short-term statin therapy improves cardiac function and symptoms in patients with idiopathic dilated cardiomyopathy. Circulation 108: 839-843, 2003.

33. Radigan KA, Urich D, Misharin AV, et al: The effect of rosuvastatin in a murine model of influenza A infection. PLoS One 7: e35788, 2012.

34. Belser JA, Szretter KJ, Katz JM and Tumpey TM: Simvastatin and oseltamivir combination therapy does not improve the effectiveness of oseltamivir alone following highly pathogenic avian H5N1 influenza virus infection in mice. Virology 439: 42-46, 2013.

35. Zarogiannis SG, Noah JW, Jurkuvenaite A, Steele C, Matalon S and Noah DL: Comparison of ribavirin and oseltamivir in reducing mortality and lung injury in mice infected with mouse adapted A/California/04/2009 (H1N1). Life Sci 90: 440-445, 2012. 